\title{
Behavioral responses of blue crab Callinectes sapidus postlarvae to turbulence: implications for selective tidal stream transport
}

\author{
James M. Welch*, Richard B. Forward Jr, Peter A. Howd** \\ Duke University Marine Laboratory, 135 Duke Marine Lab Road, Beaufort, North Carolina 28516, USA
}

\begin{abstract}
Postlarvae (megalopae) of the blue crab Callinectes sapidus move up estuaries using selective tidal stream transport, in which they are in the water column on flood tides and at or near the bottom at other times. They have no endogenous tidal rhythm in activity, so this behavior must be driven by reactions to exogenous environmental cues. Previous work indicated that rates of increase of salinity cue megalopae to ascend into the water column at the beginning of flood tide. However, this ascent due to salinity changes is a short-term response which cannot explain the duration of transport during flood tide or the descent at the end of flood tide. The present study examined turbulence in flow as a cue to regulate swimming behavior during selective tidal stream transport. Laboratory flow tank experiments show that megalopae react to increases in turbulent kinetic energy (TKE) by ascending in the water column and react to decreases in TKE by descending. Above a threshold TKE, megalopae are stimulated to swim regardless of changes in TKE. Reactions to turbulence were similar whether TKE was generated by variations in flow speed or bottom roughness. A model for the joint regulation of selective tidal stream transport by salinity and turbulence is proposed, in which increases in salinity cue the ascent in the water column at the beginning of flood tide, TKE cues swimming throughout the flood tide, and decreases in TKE cue the descent in the water column at the end of flood tide.
\end{abstract}

KEY WORDS: Turbulence - Callinectes sapidus - Blue crab - Selective tidal stream transport . Megalopae $\cdot$ Postlarvae $\cdot$ Currents

\section{INTRODUCTION}

Blue crab postlarvae (megalopae) reinvade estuaries after offshore larval development, and must move upstream to settlement sites in an environment where the net subtidal flow is seaward. Megalopae move upestuary using selective tidal stream transport (STST), in which they are in the water column on flood tides and scarce in the water column at all other times (Little \& Epifanio 1991, De Vries et al. 1994, Olmi 1994). In addition, megalopae in estuarine water exhibit a nega-

\footnotetext{
- Present address: Harbor Branch Oceanographic Institution, 5600 US Hwy 1 North, Ft. Pierce, Florida 34946, USA.

E-mail: jim.welch@duke.edu

- Present address: Department of Marine Sciences, University of South Florida, 1407 th Avenue South, St. Petersburg, Florida 33701-5016, USA
}

tive photoresponse, which keeps them near the bottom during daylight, so they are only in the water column during nighttime flood tides (Forward \& Rittschof 1994). The simplest mechanism to control STST is an endogenous tidal rhythm in activity, in which megalopae are active during flood and inactive during ebb. Such a rhythm probably contributes to STST of fiddler crab Uca spp. postlarvae, but blue crab megalopae lack a tidal rhythm (Tankersley \& Forward 1994, Forward et al. 1997). Instead, blue crab megalopae have a circadian rhythm in which they are active during the day and inactive at night. This mismatch between their endogenous rhythm and their observed behavior in the field indicates that STST in blue crab megalopae is controlled by reactions to exogenous cues, rather than by an endogenous rhythm.

Evidence suggests that the cue responsible for initiating swimming is an increase in salinity associated 


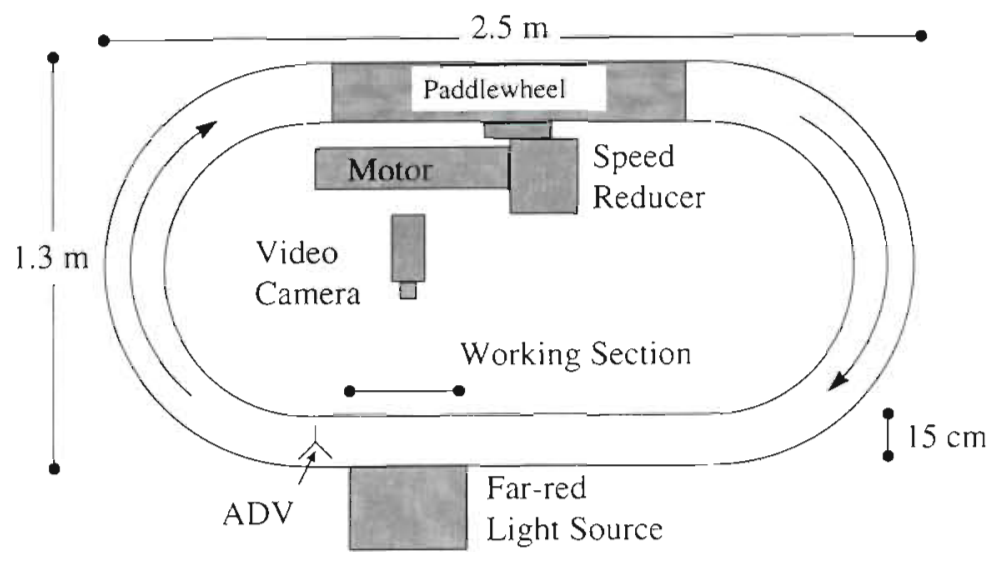

Fig. 1. Flow tank used in experiments. The tank walls were $6.25 \mathrm{~mm}$ Plexiglas, except for the inner walls of the curved sections, which were $4.75 \mathrm{~mm}$ Plexiglas. The tank is sealed with $3 \mathrm{M} 5200$ Marine Adhesive Sealant. The tank has a $15 \times 15 \mathrm{~cm}$ cross section, and its total volume is approximately $130 \mathrm{l}$. The center-channel circumference of the tank is $518 \mathrm{~cm}$. Arrows show flow direction during experiments. ADV represents the placement of the acoustic Doppler velocimeter (Sontek) used for flow measurements. The paddlewheel is $1 \mathrm{~m}$ in diameter, has 16 blades, and is driven by a $0.75 \mathrm{hp} \mathrm{DC}$ motor. The motor output is stepped down through a speed reducer $(29: 1)$ which is connected to the paddlewheel axle by a gearbelt as follows: after megalopae are stimulated to ascend into the water column by the rates of increase in salinity, tidally-generated turbulence stimulates them to continue swimming in the water column for the duration of the flood tide. At slack water after flood tide, the water motion decreases and turbulence drops to lower levels. The megalopae, no longer receiving a cue to swim, descend to the bottom to await the next nocturnal flood tide. They do not ascend from the bottom during daytime flood tides because light inhibits an ascent except in deep channels of estuaries (Forward \& Rittschof 1994, Olmi 1994).

The present study tested the hypotheses that (1) turbulence stimulates swimming in blue crab megalopae and (2) decreasing turbulence cues megalopae to descend in the water column. Both hypotheses were verified in laboratory experiments.

\section{METHODS}

with flood tides (Tankersley et al. 1995). In laboratory experiments, blue crab megalopae rise into the water column in response to increases in salinity. Megalopae have adequate sensitivity to changes in salinity because their lowest detectable rate of salinity increase $\left(5 \times 10^{-4} \mathrm{psu} \mathrm{s}^{-1}\right)$ is lower than rates of salinity increase measured in estuarine field studies (up to $1.5 \times 10^{-3}$ psu s$^{-1}$, De Vries et al. 1994, Welch 1998). However, this cue can only evoke the initial behavior involved in STST. Once megalopae are in the water column, they no longer experience significant salinity changes because they are carried with a given parcel of water. Thus, there must be a cue or cues which cause the megalopae to remain swimming during the flood tide and to descend to the bottom at the end of flood tide. A likely candidate for this cue is the variation in turbulence during flood tide.

Early work on interactions of turbulence and organisms concentrated mainly on the effects of turbulence on contact rates between planktonic predators and their prey (e.g. Rothschild \& Osborn 1988, MacKenzie \& Leggett 1991). However, more recent work has examined direct effects of turbulence on behavior of planktonic organisms. Saiz \& Alcaraz (1992) showed that turbulence stimulates increased swimming activity in zooplankters, and Alcaraz et al. (1994) found that turbulence increased the metabolic rates of zooplankton.

If turbulence stimulates swimming activity in blue crab megalopae, then a proposed model for the cues and behavior during selective tidal stream transport is
Flow tank. Experiments were conducted in a recirculating, paddlewheel-driven, racetrack flume (Fig. 1). The flume was $2.4 \mathrm{~m}$ long and $1.3 \mathrm{~m}$ wide, with a $15 \times$ $15 \mathrm{~cm}$ cross-section flow channel. It had straight drive and working sections connected by semicircular ends. The $1 \mathrm{~m}$ diameter, 16 blade paddlewheel was driven by a $0.75 \mathrm{hp} \mathrm{DC}$ motor controlled by an analog speed controller. This system produced water flow speeds from $0.25 \mathrm{~cm} \mathrm{~s}^{-1}$ to approximately $50 \mathrm{~cm} \mathrm{~s}^{-1}$ in the flume. The flow tank was inside a light-tight room and the speed control, monitoring of megalopal behavior by video, and computer monitoring of flow measurements was performed from outside the room.

Flow measurements and turbulence quantification. Measurements of flow characteristics were made with an acoustic Doppler velocimeter (Sontek ADV Field). The ADV measured current velocities on 3 orthogonal axes at $25 \mathrm{~Hz}$. The sampling volume was a cylinder approximately $6 \mathrm{~mm}$ in diameter and $9 \mathrm{~mm}$ high, with a total volume $\sim 0.25 \mathrm{~cm}^{3}$. The sensor was oriented such that the $y$-axis was parallel to the current flow, the $x$ axis was perpendicular to the current flow, and the $z$ axis was vertical. A 2 -axis bubble level was used to ensure that the ADV was vertical.

Turbulence was quantified as turbulent kinetic energy (TKE) (Marrasé et al. 1990, Peters \& Gross 1994). TKE is calculated as

$$
\mathrm{TKE}=\frac{1}{2}\left(s_{x}^{2}+s_{y}^{2}+s_{z}^{2}\right)
$$


where $s_{x}^{2}, s_{y}^{2} s_{z}^{2}$ represent the variance of the velocities along the $x-, y$-, and $z$-axes, respectively. TKE levels in these laboratory experiments $\left(-3.4 \mathrm{~cm}^{2} \mathrm{~s}^{-2}\right)$ were comparable to those measured during tidal flow in the local estuary $\left(\sim 4 \mathrm{~cm}^{2} \mathrm{~s}^{-2}\right.$, Newport River Estuary, USA, Welch 1998). The turbulent kinetic energy dissipation rate, $\varepsilon$, was also calculated using the method of Saiz (1994). Levels of $\varepsilon$ in the flume ranged from $2 \times 10^{-2}$ to $3 \times$ $10^{1} \mathrm{~cm}^{2} \mathrm{~s}^{-3}$, compared to $2 \times 10^{-2}$ to $1 \times 10^{1} \mathrm{~cm}^{2} \mathrm{~s}^{-3}$ in the field (Welch 1998). In the flow conditions used in experiments, flow Reynolds numbers varied from $-2 \times 10^{3}$ to $3 \times 10^{5}$, compared to $\sim 5 \times 10^{4}$ to $4 \times 10^{6}$ in the field.

General experimental procedure. Megalopae of the blue crab Callinectes sapidus Rathbun were collected using a plankton net $(0.67 \mathrm{~m}$ diameter, $505 \mu \mathrm{m})$ suspended from the Pivers Island bridge, near Beaufort, NC, USA, during nighttime flood tides. Megalopae were held until experimentation in $19 \mathrm{~cm}$ diameter finger bowls containing offshore seawater. Offshore water was collected $15 \mathrm{~km}$ seaward of Beaufort Inlet and had a salinity of 35 psu as measured with a refractometer (AO). This water was beyond the estuarine plume and from an area where megalopae were collected previously in the neuston (Forward \& Rittschof 1994). Megalopae were maintained in offshore water to reduce exposure to estuarine chemical cues that accelerate metamorphosis (Forward et al. 1996). They were not separated according to molt stage prior to experiments. Bowls were held in a controlled environment chamber (Sherer model CEL-4) at $23^{\circ} \mathrm{C}$ and a $14 \mathrm{~h}$ light: $10 \mathrm{~h}$ dark photoperiod (light intensity from cool white fluorescent lamps $=6.2 \times 10^{15}$ photons $\mathrm{cm}^{-2}$ $\mathrm{s}^{-1}$ j. Water in the bowls was changed daily, and megalopae were fed an excess of newly hatched Artemia franciscana nauplii.

The flow tank was filled with either offshore water, defined above, or with estuarine water. Estuarine water (salinity 32 to 34 psu) was collected by bucket from a dock at the Duke University Marine Laboratory, Beaufort, NC, USA near the end of ebb tides Estuarine water was not filtered prior to use in experiments. The flow tank was filled the day before experiments began, to allow the water to come to room temperature $\left(-23^{\circ} \mathrm{C}\right)$. Water was used in experiments for a maximum of $3 \mathrm{~d}$ before it was changed. At least $2 \mathrm{~h}$ before experiments began, 100 megalopae were transferred from the holding bowls into a bowl containing water from the flow tank. Megalopae were added to the flow tank at least 10 min before experiments began to allow them to recover from any disturbance caused by addition to the tank and to adapt to the dark experimental conditions. These times should be sufficient to allow the megalopae to recover from any slight salinity change between the different waters (Latz \& Forward 1977) and to resume normal swimming after the decrease in light intensity (Forward \& Rittschof 1994).

During experiments, positions of the megalopae in the water column were recorded using a closed circuit video system (Cohu model 4815 video camera connected to a Panasonic model NV-8950 video recorder). Experiments were conducted in the dark, but megalopae were illuminated using far-red light (maximum transmission $775 \mathrm{~nm}$ ). Light of this wavelength is imperceptible to megalopae (Cronin \& Forward 1988), but perceived by the camera. The video system was aligned horizontally to view the entire water column from top to bottom.

Experiments varying turbulent kinetic energy by varying flow speed. The first set of experiments considered the effects of variations in flow speed on behavior of megalopae. Experiments were run in both offshore and estuarine water to see if responses to turbulence varied with water type, as Forward \& Rittschof (1994) found that photobehavior varied in offshore and estuarine water. Five trials were conducted in each water type. Experiments began in still water, and the speed was increased to $20 \mathrm{~cm} \mathrm{~s}^{-1}$ in steps $(0,0.25,1.25$, $2.5,5,10$, and $20 \mathrm{~cm} \mathrm{~s}^{-1}$ ) at 4 min intervals and then stepped back down to zero. After a speed change, 1 min was allowed for the flow to stabilize, and then counting began. Megalopae were counted as being either in the top half or bottom half of the water column. In order to avoid counting the same megalopa twice during a given sampling period (to ensure independence of data), no counting period was longer than the time for a complete circuit of the water around the flume at that flow speed. Thus, the period of counting varied from $3 \mathrm{~min}$ at flow speeds $\leq 2.5 \mathrm{~cm} \mathrm{~s}^{-1}$ to $20 \mathrm{~s}$ at $20 \mathrm{~cm} \mathrm{~s}^{-1}$. At slow speeds, the swimming speed of the megalopae is much greater than the speed of the water. This can result in megalopae being observed in the working section, swimming away, turning around, and returning to the working section during a given counting period. For this reason, if a megalopa was observed swimming with frequent directional changes and swam out of the working section and reappeared in the same location within a second, it was not counted as a new megalopa. Overall, it is unlikely that this behavior affected the observed results. Since different amounts of water passed through the working section during a counting period for the different flow speeds, raw counts of numbers of megalopae in the top half of the water column would presumably increase with the amount of water monitored. Thus, all megalopae were counted and the response variable used was the proportion of megalopae seen during the counting period that were in the top half of the water column. Results were analyzed using a repeated-measures ANOVA (ANOVAR, Gurevitch \& Chester 1986), with water type as an additional factor (SYSTAT 1996). 


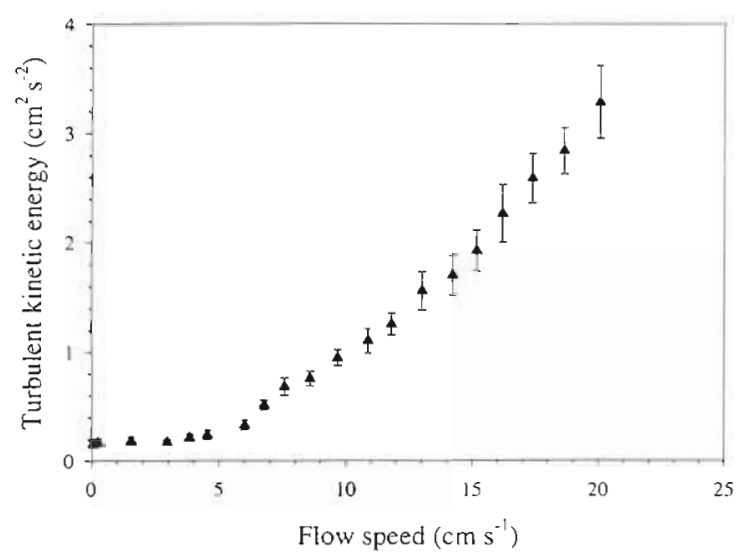

Fig. 2. Turbulent kinetic energy versus flow speed in flume. Values are means \pm SE $(n=10)$ of turbulent kinetic energy at flow speeds indicated

Experiments varying turbulent kinetic energy by varying bottom roughness. As flow speed increased in the flume, so did measured turbulence (Fig. 2). To explicitly test the hypothesis that turbulence was responsible for the observed behavioral changes, a second set of experiments was conducted in which turbulence was varied independently of flow speed. This was accomplished by perturbing the flow by adding roughness elements while keeping the flow speed constant. Roughness elements were smooth rocks, ovoid in shape, 2.5 to $3.0 \mathrm{~cm}$ on the major axis and 1.5 to $2.0 \mathrm{~cm}$ on the minor axis. Rocks were added in rough piles of approximately 25 rocks placed 40 to $70 \mathrm{~cm}$ upstream of the working section of the flume. Experiments proceeded as follows, with 5 min for each condition: still water; flow with no rocks; flow with 2 piles of rocks; flow with 4 piles of rocks; flow with 2 piles of rocks; flow with no rocks; still water. Behavioral counting took place for the last $2 \mathrm{~min}$ of each condition. Flow speed and turbulence measurements were made during the first minute of behavioral counting. Experiments were performed at current speeds of $1.25,2.5$, and $5 \mathrm{~cm} \mathrm{~s}^{-1}$ to examine whether responses to turbulence were based on absolute levels of turbulence, absolute changes in turbulence, or relative changes in turbulence. Since no difference in behavior was found in offshore and estuarine water in the first set of experiments, these experiments were performed solely in estuarine water. Results for each speed were analyzed using repeated measures ANOVA (SYSTAT 1996).

Experiments with anesthetized megalopae. To ensure that megalopae observed in the water column were actually swimming and not merely being picked up by the water flow, an experiment was run with anesthetized megalopae. Anesthetized megalopae were used rather than killed or preserved megalopae to ensure that osmotic balances and densities of megalopae were not altered.
Megalopae were anesthetized using propylene phenoxital (Spectrum Chemical, \#PR132), which has been used previously in sinking rate determinations of live crab larvae (Latz \& Forward 1977). One hundred megalopae were placed in a $100 \mathrm{ml}$ beaker with $50 \mathrm{ml}$ of estuarine water. Approximately $2 \mathrm{ml}$ of propylene phenoxital was added to the surface of the water. As megalopae ceased activity (beginning in 12 to $15 \mathrm{~min}$ ), they were transferred by pipette to a bowl containing clean flow tank water. Once all megalopae were transferred, they were moved to a second bowl of clean flow tank water, to avoid introducing excess anesthetic to the flow tank. Megalopae remained inactive for 20 to $30 \mathrm{~min}$ after exposure to anesthetic. Survival after exposure (measured as the number of megalopae swimming in a bowl after 2 h) was 80 to $90 \%$, indicating that the majority of the megalopae were indeed anesthetized and not dead. Anesthetized megalopae were placed in the working section of the flow tank and exposed to all flow regimes experienced in the experiments. The number of megalopae in the upper half of the water column was counted using the video system as in previous experiments. Four replicate trials were performed, each with 100 anesthetized megalopae.

\section{RESULTS}

\section{General behavior of megalopae and results with anesthetized megalopae}

The video records clearly indicate that normal megalopae were actively swimming in the flume. They were always oriented dorsal side up, and almost always

Table 1. Repeated measures ANOVA for experiments in which TKE was varied by varying flow speed. Dependent variable is proportion of megalopae in the top half of the water column at each step of experiment. $n=5$ runs per water type

\begin{tabular}{|c|c|c|c|c|}
\hline & df & MS & $F$ & $\mathrm{p}$ \\
\hline \multicolumn{5}{|c|}{ Univariate repeated measures analysis } \\
\hline \multicolumn{5}{|l|}{ Between subjects } \\
\hline Water type & 1 & 0.011 & 0.319 & 0.585 \\
\hline Error & 9 & 0.034 & & \\
\hline \multicolumn{5}{|l|}{ Within subjects } \\
\hline Time & 13 & 0.211 & 25.992 & $<<0.001$ \\
\hline Time $\times$ Water type & 13 & 0.002 & 0.310 & 0.989 \\
\hline Error & 117 & 0.008 & & \\
\hline \multicolumn{5}{|c|}{ Single degree of freedom contrast } \\
\hline \multicolumn{5}{|c|}{ Polynomial test of order 2 (quadratic) } \\
\hline Time & 1 & 2.071 & 119.127 & $<<0.001$ \\
\hline Time $\times$ Water type & 1 & 0.007 & 0.385 & 0.550 \\
\hline Error & 9 & 0.017 & & \\
\hline
\end{tabular}


(>90\%) oriented either directly upstream or directly downstream. Anesthetized larvae were never observed in the water column except at the fastest test speed of $20 \mathrm{~cm} \mathrm{~s}^{-1}$. In $20 \mathrm{~cm} \mathrm{~s}^{-1}$ flow, an average of $1.08 \pm 0.25$ (mean $\pm \mathrm{SE} ; \mathrm{n}=4$ ) megalopae per circuit of water was observed in the top half of the water column. However, these megalopae were ventral side up, as opposed to actively swimming megalopae, which were always dorsal side up. In all other flow conditions, anesthetized larvae either stayed on the bottom in place or rolled along the bottom, staying out of the water column at all times. Therefore, it was concluded that all megalopae observed in the top half of the water column during experiments were there by active swimming, rather than by being swept up by the water flow.

\section{Experiments varying turbulent kinetic energy by varying flow speed}

As flow speed increased, observed turbulence also increased (Fig. 2). The proportion of megalopae in the top half of the water column increased with increasing TKE and decreased as TKE decreased (Fig. 3; ANOVAR, quadratic trend $\mathrm{p} \ll 0.001$, Table 1 ). There was no difference in behavior between experiments conducted in offshore and estuarine water (Fig. 3; ANOVAR, all interaction terms $\mathrm{p}>0.05$, Table 1). Because selective tidal stream transport occurs in estuaries, further experiments were conducted solely in estuarine water.

\section{Experiments varying turbulent kinetic energy by varying bottom roughness}

The addition of bottom roughness elements increased turbulence in the flow tank (Fig. 4). TKE was lowest in still water, increased with flow, and increased further with the addition of rocks. The positions of megalopae in the water column showed the same pattern. Megalopae swam higher as TKE increased, and descended

Fig. 4. Callinectes sapidus. Results of experiments varying TKE by varying bottom roughness at constant speeds. Nominal flow speeds were (a) $1.25 \mathrm{~cm} \mathrm{~s}^{-1}$, (b) $2.5 \mathrm{~cm} \mathrm{~s}^{-1}$, and (c) $5.0 \mathrm{~cm} \mathrm{~s}^{-1}$. Time steps represent step changes in flow conditions (see text for details). Percent responding is the percentage of megalopae in the top half of water column. Percent responding is plotted with circles and solid lines, turbulent kinetic energy with triangles and dashed lines. Means \pm SE are plotted $(n=5)$. TKE measurements were taken during experimental runs. Note the different scales for turbulent kinetic energy axes

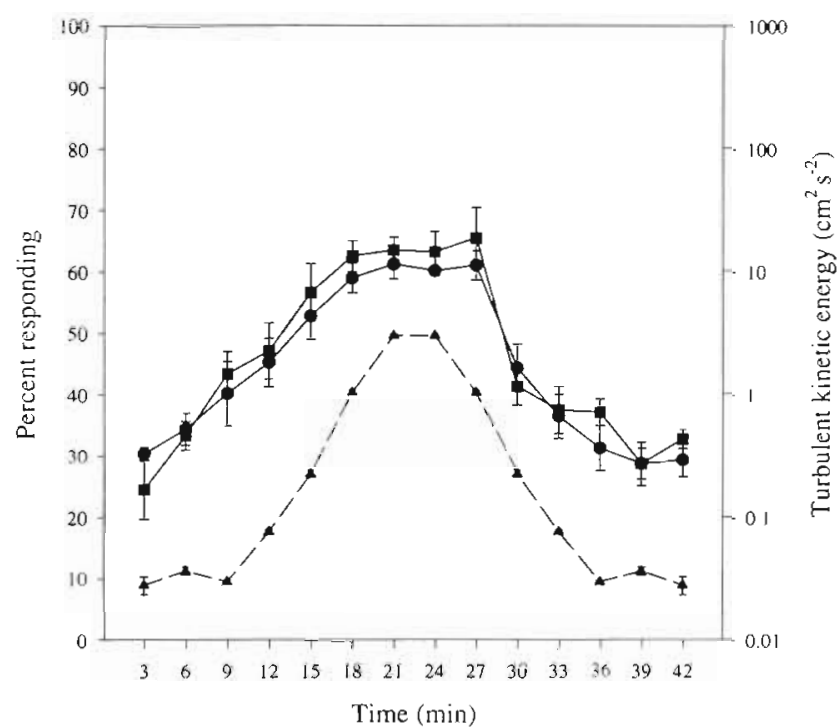

Fig. 3. Callinectes sapidus. Results of experiments varying TKE by varying flow speed. Percent responding is the percentage of megalopae in the top half of water column, shown with solid lines. Experiments in offshore water are shown with circles, experiments in estuarine water with squares. Means \pm SE are shown $(n=5)$. TKE measures $(n=5)$ were made independently of experimental runs and mean values are indicated by the triangles with dashed lines. Time steps also represent changes in flow velocity

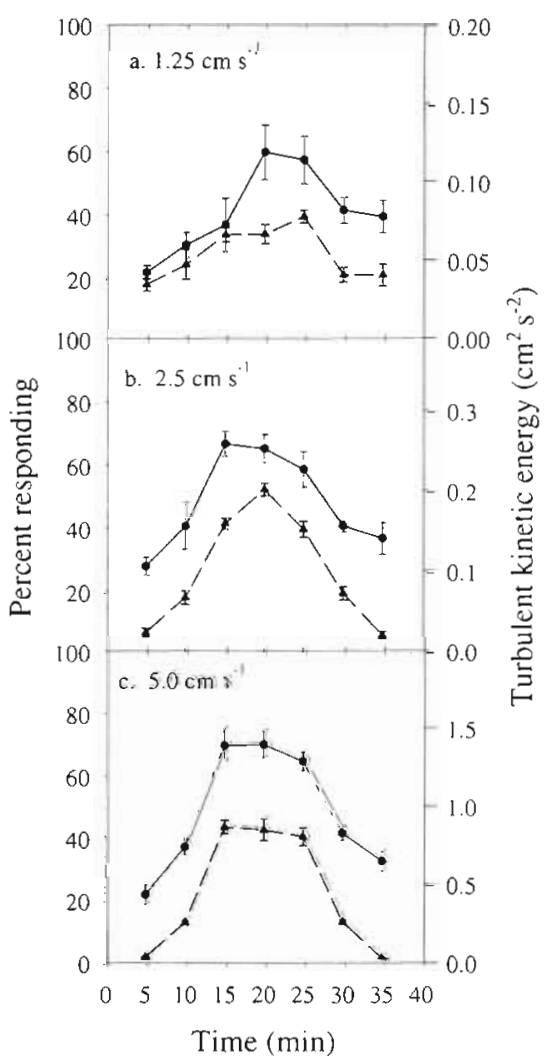


Table 2. Repeated measures ANOVA for experiments in which TKE was varied by varying bottom roughness. Dependent variable is proportion of megalopae in the top half of the water column at each step of experiment. $n=5$ runs per flow speed

\begin{tabular}{|c|c|c|c|c|}
\hline & df & MS & $F$ & $\mathrm{p}$ \\
\hline \multicolumn{5}{|c|}{ a. Speed $=1.25 \mathrm{~cm} \mathrm{~s}^{-1}$} \\
\hline \multicolumn{5}{|c|}{ Univariate repeated measures analysis } \\
\hline \multicolumn{5}{|c|}{ Within subjects } \\
\hline Time & 6 & 0.094 & 7.455 & $<0.001$ \\
\hline Error & 24 & 0.013 & & \\
\hline \multicolumn{5}{|c|}{ Single degree of freedom polynomial contrast } \\
\hline \multicolumn{5}{|c|}{ Polynomial test of order 2 (quadratic) } \\
\hline Time & 1 & 0.277 & 18.794 & 0.012 \\
\hline Error & 4 & 0.015 & & \\
\hline \multicolumn{5}{|c|}{ b. Speed $=2.5 \mathrm{~cm} \mathrm{~s}^{-1}$} \\
\hline \multicolumn{5}{|c|}{ Univariate repeated measures analysis } \\
\hline \multicolumn{5}{|c|}{ Within subjects } \\
\hline Time & 6 & 0.116 & 11.785 & $<0.001$ \\
\hline Error & 24 & 0.009 & & \\
\hline \multicolumn{5}{|c|}{ Single degree of freedom polynomial contrasts } \\
\hline \multicolumn{5}{|c|}{ Polynomial test of order 2 (quadratic) } \\
\hline Time & 1. & 0.583 & 26.649 & 0.007 \\
\hline Error & 4 & 0.022 & & \\
\hline \multicolumn{5}{|c|}{ c. Speed $=5.0 \mathrm{~cm} \mathrm{~s}^{-1}$} \\
\hline \multicolumn{5}{|c|}{ Univariate repeated measures analysis } \\
\hline \multicolumn{5}{|c|}{ Within subjects } \\
\hline Time & 6 & 0.194 & 37.409 & $<<0.001$ \\
\hline Error & 24 & 0.005 & & \\
\hline \multicolumn{5}{|c|}{ Single degree of freedom polynomial contrast } \\
\hline Time & 1 & 1.011 & 205.053 & $<0.001$ \\
\hline Error & 4 & 0.004 & & \\
\hline
\end{tabular}

as it decreased (Fig. 4; ANOVAR, quadratic trends all $p<0.05$, Table 2). These relationships were the same in all 3 experimental flow speeds. However, different numbers of megalopae swam in response to similar absolute amounts of TKE in the 3 experimental speeds (Fig. 5). This indicates that megalopae did not simply respond to absolute levels of turbulent kinetic energy. Changes in TKE were calculated as the difference in turbulent kinetic energy between adjacent experimental steps ( $\triangle T K E)$. If the TKE increases, $\triangle T K E$ is positive, if it decreases, $\triangle \mathrm{TKE}$ is negative. Relative changes in TKE were calculated as $\triangle T K E /$ initial TKE. Megalopae did not respond to absolute changes in TKE (Fig. 6), or to relative changes in TKE (Fig. 7), because in both cases, similar responses were cued by changes in TKE of similar magnitude but opposite signs.

Another way to examine swimming activity is to consider the change in swimming activity between adjacent experimental steps, rather than the absolute amount of swimming. Changes in response were cal-

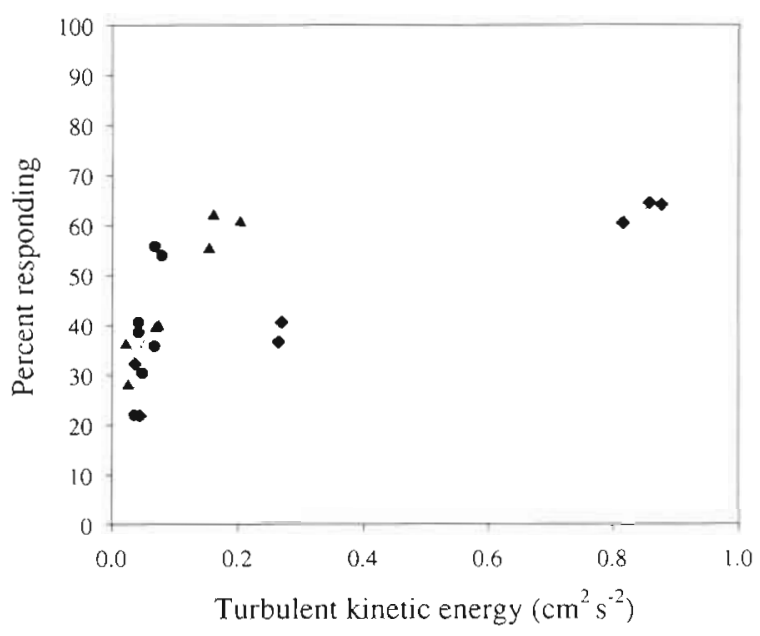

Fig. 5. Callinectes sapidus. Swimming activity versus absolute turbulent kinetic energy. Results from $1.25 \mathrm{~cm} \mathrm{~s}^{-1}$ flow speed experiment are plotted with circles, $2.5 \mathrm{~cm} \mathrm{~s}^{-1}$ results with triangles, and $5 \mathrm{~cm} \mathrm{~s}^{-1}$ results with diamonds. Mean values are plotted $(n=5)$. Dashed lines are linear regressions for each speed; $\mathrm{r}^{2}$ values are 0.56 for $1.25 \mathrm{~cm} \mathrm{~s}^{-1}, 0.92$ for $2.5 \mathrm{~cm} \mathrm{~s}^{-1}$, and 0.96 for $5 \mathrm{~cm} \mathrm{~s}^{-1}$

culated as the difference between percent responding between adjacent experimental steps. There was a saturating dose-response relationship between the relative change in TKE and the change in swimming activity (Fig. 8). Increases in TKE cued increased swimming responses and decreases in TKE cued decreased swimming responses. Increases in swimming activity were small with small relative increases in TKE, but rapidly saturated at high relative increases in TKE (Fig. 8).

\section{DISCUSSION}

These results clearly indicate that blue crab megalopae respond to changes in turbulence by changing their swimming behavior, and were not being passively swept into the water column. Megalopae ascended into the water column in response to increasing $T K E$, and descended in the water column in response to decreasing TKE. This held true whether the turbulence was generated by increasing the flow speed of the water or by increasing bottom roughness.

The experiments with varying bottom roughness suggest that megalopae respond to changes in turbulence rather than to absolute amounts of turbulence. Similar absolute levels of TKE resulted in widely different swimming responses (Figs. 4 \& 5). Also, the absolute percentage of megalopae swimming could not be predicted by either the absolute or relative change in TKE (Figs. $6 \& 7$ ). Often, however, animals 


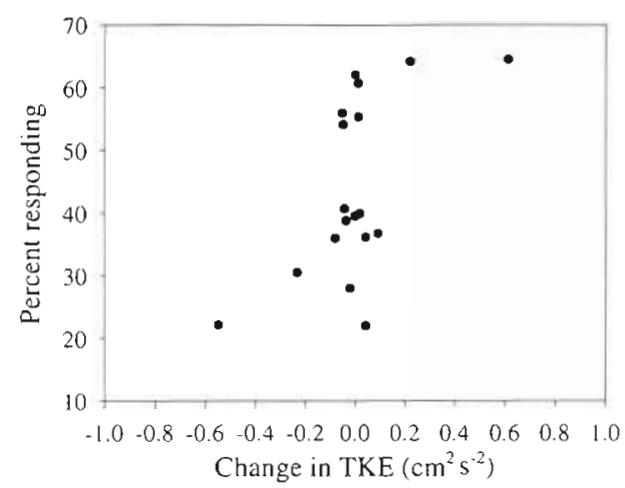

Fig. 6. Callinectes sapidus. Swimming activity versus absolute changes in turbulent kinetic energy. Absolute change in TKE is the difference between TKE in adjacent experimental steps. Mean values are plotted $(n=5)$

change their behavior in response to changes in environmental cues (e.g. Tankersley et al. 1995). Thus, while the change in TKE cannot predict the absolute response of the megalopae (Figs. 6\& 7), it is a good predictor of the change in their response (Fig. 8). Increases in TKE increased swimming by the megalopae, and decreases in TKE decreased megalopal swimming. This pattern of changes in behavior in response to changes in environmental cues is common for zooplankton. Crab larvae ascend and descend in response to changes in light (Forward 1985), salinity (Tankersley et al. 1995), and pressure (Tankersley et al. 1995).

However, there also appears to be a threshold TKE above which megalopae are stimulated to swim regardless of changes in TKE. In the experiments with varying flow speed (Fig. 3), the maximal behavioral response was achieved at a TKE level of $1.1 \mathrm{~cm}^{2} \mathrm{~s}^{-2}$, at a flow speed of $10 \mathrm{~cm} \mathrm{~s}^{-1}$. In the next step, TKE increased by $\sim 200 \%$ but there was no further increase in swimming by the megalopae. The relationship shown in Fig. 8 would have predicted an increase in swimming activity with such a large relative increase in turbulence. Further, in the step from $20 \mathrm{~cm} \mathrm{~s}^{-1}$ to $10 \mathrm{~cm} \mathrm{~s}^{-1}$ (Fig. 3), TKE decreased by $\sim 67 \%$ with no corresponding descent by the megalopae, while a descent would have been predicted. When the flow speed decreased from $10 \mathrm{~cm} \mathrm{~s}^{-1}$ to $5 \mathrm{~cm} \mathrm{~s}^{-1}$, reducing the TKE by $\sim 75 \%$, megalopae descended steeply in the water column, as would be predicted by the relationship in Fig. 8 (Fig. 3). This suggests that there is a threshold near $1.1 \mathrm{~cm}^{2} \mathrm{~s}^{-2}$ above which changes in TKE do not result in changes in swimming behavior because megalopae are always maximally stimulated to swim. During slack water in the Newport River Estuary, NC, levels of TKE are below $1 \mathrm{~cm}^{2} \mathrm{~s}^{-2}$ (Welch 1998).

Taken together, these results indicate that turbulence is a likely factor involved in the regulation of selective

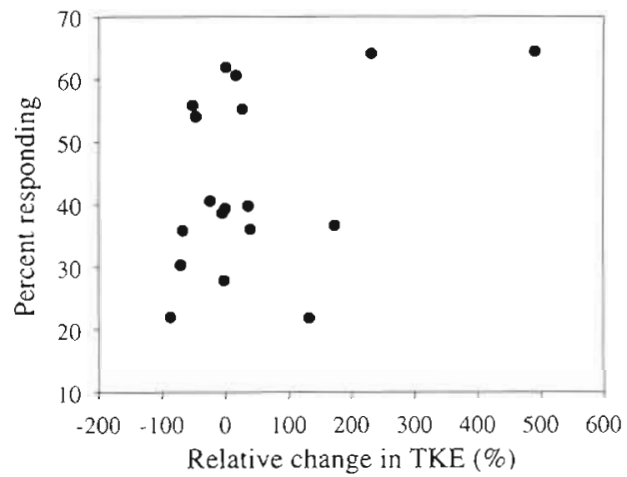

Fig. 7. Callinectes sapidus. Swimming activity versus relative changes in turbulent kinetic energy. Relative change in TKE is the difference in TKE between adjacent experimental steps, divided by the initial TKE. Mean values are plotted ( $n=5$ )

tidal stream transport in blue crab megalopae. Blue crab megalopae have an endogenous diel rhythm in activity, not a tidal rhythm (Tankersley \& Forward 1994, Forward et al. 1997). Thus, their observed tidally timed transport mechanism must be regulated by exogenous cues and not an endogenous activity cycle. While increasing salinity is a reliable cue for the beginning of flood tides (De Vries et al. 1994, Tankersley et al. 1995), a salinity change cannot induce a sustained swimming response or signal the end of flood tide. Once a megalopa is in the water column, it travels with a particular parcel of water, the salinity of which will remain relatively constant, even during the ensuing ebb tide. Furthermore, Latz \& Forward (1977) found that increases in swimming activity of crab larvae due to a salinity

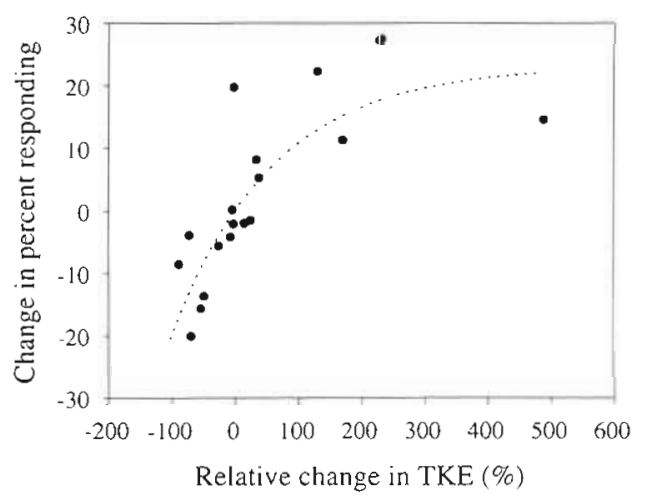

Fig. 8. Callinectes sapidus. Change in swimming activity versus relative change in turbulent kinetic energy. Change in swimming activity is the difference between percent responding in adjacent experimental steps. Relative change in TKE is the difference in TKE between successive experimental steps, divided by initial TKE in the initial step. Mean values are plotted $(\mathrm{n}=5$ ). Dotted line is nonlinear regression of best fit with the equation $\Delta$ Resp $=0.234 \mathrm{e}^{-0.00624 \Delta \text { Turb }}$, where $\Delta$ Resp is change in percent response and $\Delta$ Turb is the relative change in turbulence, $\left(\mathrm{r}^{2}=0.66\right.$, SYSTAT $)$ 
change last only a few minutes, not the several hours during which megalopae are transported during the flood tide. Clearly, salinity does not control all activities involved in STST. In contrast, turbulence (measured as TKE or as $\varepsilon$ ) varies with tidal state, being higher during both ebb and flood tide than at slack water (McMurray 1980, Welch 1998). Thus, tidally generated turbulence could serve as a cue regulating the 3 phases of STST (ascent at the beginning of flood tide, maintenance in the water column during flood tide, and descent at the end of flood tide) as follows: After increases in salinity cue megalopae to ascend in the water column, increasing TKE associated with the accelerating flood tide stimulates swimming by the megalopae. Since increases in swimming activity of zooplankters causes an ascent (Rudjakov 1970), megalopae would continue to ascend. During most of flood tide. TKE levels would be above the threshold, so megalopae would be continually stimulated to swim and remain in the water column. At the end of flood tide, the TKE drops below the threshold and the relative rate of decrease in TKE cues decreasing swimming, and thus a descent, by the megalopae.

In order for this mechanism to explain STST, megalopae must not swim up into the water column in response to the turbulence generated by the ebb tide. Either of 2 mechanisms could prevent this ascent from happening. First, if megalopae require a salinity increase to begin swimming in the water column, they would not get this cue during an ebb tide. A second, and more likely, possibility is that a salinity decrease, as would be experienced by a megalopa on the bottom at the beginning of ebb tide, could actually suppress swimming behavior. Further research is needed to differentiate between these possibilities and to examine the time course of responses to turbulence. While the present experiments showed megalopae respond to short duration changes in TKE, it will be necessary to demonstrate that turbulence can keep megalopae swimming for periods of time similar to the duration of flood tides to further substantiate the involvement of turbulence in selective tidal stream transport of blue crab megalopae.

In conclusion, blue crab megalopae swim in response to increasing turbulence and descend in the water column in response to decreasing turbulence. Results indicate that changes in TKE, not absolute levels, are responsible for the behavior, except that there is a threshold level of TKE above which megalopae are always stimulated to swim. Although further research is necessary, these results are consistent with the proposed model of behavior during STST: the rate of salinity increase during flood tide evokes an ascent into the water column, megalopae remain swimming through the flood tide in response to turbulence in the flow, and then descend to the bottom when turbulence decreases at the end of flood tide.
Acknowledgements. This material is based on research supported by the National Science Foundation (OCE-9216629) and North Carolina Sea Grant (NA56FE055). The authors wish to thank Dr. Steven Vogel for his advice on flow tank design and construction, Dimitri Blondel for technical assistance and megalopa collection and Dr. Richard Tankersley for statistical consultation. Special thanks go to Bill Hunnings for his invaluable assistance in the construction of the flume.

\section{LITERATURE CITED}

Alcaraz M, Saiz E, Calbet A (1994) Small-scale turbulence and zooplankton metabolism: effects of turbulence on heartbeat rates of planktonic crustaceans. Limnol Oceanogr 39:1465-1470

Cronin TW, Forward RB Jr (1988) The visual pigments of crabs I. Spectral characteristics. J Comp Physiol A 162: 463-478

De Vries MC, Tankersley RA, Forward RB Jr, Kirby-Smith WW, Luettich RA Jr (1994) Abundance of estuarine crab larvae is associated with tidal hydrologic variables. Mar Biol 118:403-413

Forward RB Jr (1985) Behavioral responses of larvae of the crab Rhithropanopeus harrisii (Brachyura: Xanthidae) during diel vertical migration. Mar Biol 90:9-18

Forward RB Jr, Rittschof D (1994) Photoresponses of crab megalopae in offshore and estuarine waters: implications for transport. J Exp Mar Biol Ecol 182:183-192

Forward RB $J r_{1}$ De Vries MC, Rittschof D, Frankel DAZ, Bischoff JP, Fisher CM, Welch JM (1996) Effects of environmental cues on metamorphosis of the blue crab Callinectes sapidus. Mar Ecol Prog Ser 131:165-177

Forward RB Jr, Swanson J, Tankersley RA, Welch JM (1997) Endogenous swimming rhythms of blue crab, Callinectes sapidus, megalopae: effects of offshore and estuarine cues Mar Biol 127:621-628

Gurevitch J, Chester ST Jr (1986) Analysis of repeated mea sures experiments. Ecology 67:251-255

Latz MI, Forward RB Jr (1977) The effect of salinity upon phototaxis and geotaxis in a larval crustacean. Biol Bull 153: $163-179$

Little KT, Epifanio CE (1991) Mechanism for the re-invasion of an estuary by two species of brachyuran megalopae. Mar Ecol Prog Ser 68:235-242

MacKenzie BR, Leggett WC (1991) Quantifying the contribution of small-scale turbulence to the encounter rates between larval fish and their zooplankton prey: effects of wind and tide. Mar Ecol Prog Ser 73:149-160

Marrasé C, Costello JH, Granata T, Strickler JR (1990) Grazing in a turbulent environment: energy dissipation, encounter rates, and efficacy of feeding currents in Centropages hamatus. Proc Natl Acad Sci USA 87 1653-1657

McMurray JT (1980) Measurement of nonstationary turbulent flow in a tidal channel by laser Doppler velocimetry. PhD thesis, Duke University, Durham

Olmi EJ III (1994) Vertical migration of blue crab Callinectes sapidus megalopae: implications for transport in estuaries. Mar Ecol Prog Ser 113:39-54

Peters $F$, Gross $T$ (1994) Increased grazing rates of microplankton in response to small-scale turbulence. Mar Ecol Prog Ser 115:299-307

Rothschild BJ, Osborn TR (1988) Small-scale turbulence and plankton contact rates. J Plankton Res 10:465-474

Rudjakov JA (1970) The possible causes of diel vertical migration of planktonic animals. Mar Biol 6:98-105 
Saiz E (1994) Observations of the free-swimming behavior of Acartia tonsa: Effects of food concentration and turbulent water motion. Limnol Oceanogr 39:1566-1578

Saiz E, Alcaraz M (1992) Free-swimming behavior of Acartia clausi (Copepoda: Calanoida) under turbulent water movement. Mar Ecol Prog Ser 80:229-236

Tankersley RA, Forward RB Jr (1994) Endogenous swimming rhythms in estuarine crab megalopae: implications for flood-tide transport. Mar Biol 118:415-423

Editorial responsibility: Otto Kinne (Editor), Oldendorf/Luhe, Germany
Tankersley RA, Mckelvey LM, Forward RB Jr (1995) Responses of estuarine crab megalopae to salinity, pressure and light: implications for flood tide transport. Mar Biol 122:391-400

Welch JM (1998) Behavior of blue crab (Callinectes sapidus) megalopae during transport and settlement site selection: effects of turbulence and chemical cues. PhD thesis, Duke University, Durham

Submitted: March 9, 1998; Accepted: November 18, 1998 Proofs received from author(s): March 29, 1999 